\title{
Control de las concentraciones económicas en el marco jurídico de la Ley 601, Ley de Promoción de la Competencia
}

Melvin Javier Escobar Cerda

Instructor de procesos en la Dirección de Defensa al Consumidor del MIFIC. Residencial Don Bosco, casa E-266, Managua. Correo electrónico: Mjec31@hotmail.com

ESTE ARTÍCULO EXPLORA LA IMPORTANCIA Y NECESIDAD DE LA existencia de un marco jurídico que regule el comportamiento de las empresas en el mercado, es decir, aquellas prácticas restrictivas que tienen como finalidad evitar la competencia y controlar las estructuras del mercado. En Nicaragua se aprobó la Ley 601, Ley de Promoción de la Competencia, el 28 de septiembre de 2006 y fue publicada en La Gaceta Diario Oficial No. 206 del 24 de octubre de 2006. Sin embargo, hasta la fecha, PROCOMPETENCIA (Instituto Nacional de Promoción de la Competencia), que es el órgano cuya misión es la aplicación de la Ley, no ha sido conformado y por ende el mercado nacional, integrado por agentes económicos y consumidores, se encuentra desprotegido. Los operadores económicos más poderosos cuentan con la libertad de cometer abusos e incluso de fusionarse con otras empresas con el objetivo de alcanzar una mayor cuota de mercado que les permita establecer de manera unilateral el funcionamiento y condiciones del mismo. Este estudio explora los principales criterios que la Ley establece en materia de concentraciones.

Palabras clave: concentraciones económicas / competencia / ley / Nicaragua

\section{Introducción}

En los sistemas de economía de mercado, uno de los principios básicos es el de la libertad de empresa ${ }^{1}$. En Nicaragua este principio se encuentra comprendido en el artículo 99 de la Constitución Política y dice lo siguiente: “... el Estado garantiza la libertad de empresa...”, además el artículo 104 del mismo cuerpo jurídico expone: "Se garantiza el pleno ejercicio de las actividades económicas...”. Por lo tanto es obligación del Estado establecer un marco de competencia que permita detectar y corregir cualquier distorsión que afecte el buen funcionamiento del mercado. Para lograr esa finalidad es necesario que dicho marco jurídico defina y diferencie entre acuerdos restrictivos de la competencia, abusos de posición de dominio, competencia desleal y el control de las concentraciones económicas. 
Cuando se habla de concentraciones económicas es necesario tener en cuenta el sistema capitalista. Éste ha atravesado por dos fases históricas (Méndez Morales, 1996:43): a) Premonopolista o de libre competencia que abarca del siglo XVI al último tercio del siglo XIX; b) Imperialista o monopolista, que abarca del último tercio del siglo XIX a nuestros días. En la primera fase la competencia entre capitalistas se basaba en el costo y la calidad de los productos, es decir, se perseguía la eficiencia. En la segunda etapa predominan las sociedades anónimas, y como consecuencia a que el capital se concentra y acumula en pocas manos, algunas empresas se fusionan procurando mantenerse en la competencia. Por lo tanto, las concentraciones económicas (fusiones y adquisiciones de control) son un recurso que tienen las pequeñas y medianas empresas para obtener mayores cuotas de mercado y de esta manera generar competitividad en el mismo (Samuelson \& Nordhaus, 1999:323).

Estas concentraciones pueden producir efectos positivos y beneficiosos para la sociedad debido a que en ocasiones, a raíz de ellas, las empresas producen con mejor calidad y a menores costos, lo que significa que los consumidores serán beneficiados. A esto se le puede llamar bienestar social ${ }^{2}$. Por otro lado, las concentraciones pueden ocasionar un desequilibrio en el mercado y dañar ese bienestar social para convertirlo en beneficio de la empresa que se ha concentrado. En muchas ocasiones estas operaciones dan como resultado tanto efectos positivos como negativos, por esa razón se hace difícil tomar una decisión. Se debe hacer una valoración sobre las consecuencias de la concentración.

Cuando las fusiones o adquisiciones de control dan como resultado posiciones de dominio es necesario regularlas y analizarlas, esta es una tarea que le corresponde al Estado por medio de la institución competente.

\section{La Ley 601}

La Ley 601, en su artículo 1, establece que su objeto es promover y tutelar la competencia entre los agentes económicos mediante la prevención y la sanción de prácticas anticompetitivas ${ }^{3}$. El objeto de la Ley sintetiza las diferentes conductas dentro del concepto de prácticas anticompetitivas, aunque después el legislador acepta la diferencia porque dedica un capítulo para el caso de la competencia desleal y otro para las prácticas anticompetitivas. Por otro lado, una concentración económica no es una práctica anticompetitiva y su regulación supone un trato distinto ${ }^{4}$.

Las concentraciones no son una práctica prohibida, así lo establece el artículo 24 de la Ley 601, cuando en su parte in fine dice literalmente: "Las modalidades de concentración antes descritas no requieren notificación previa”. De manera que en principio las concentraciones son permitidas y no todas requieren de un examen previo para ejecutarse.

\subsection{Fusiones y adquisiciones de control}

Por lo general, cuando se habla de concentraciones económicas, se hace referencia a la fusión. En efecto, los agentes económicos se pueden concentrar mediante la fusión, pero además, otro procedimiento que se utiliza para lograr esa finalidad es la adquisición de control. El artículo 24 de la Ley 601 expresa literalmente lo siguiente: 
Para efectos de esta Ley se consideran concentraciones:

a) Cuando agentes económicos que han sido independientes entre sí realicen entre otros: actos, contratos, acuerdos, convenios, que tengan como finalidad la fusión, adquisición, consolidación, integración, o combinación de sus negocios en todo o en partes, dejando de ser independientes;

b) Cuando uno o más agentes económicos que ya controlan por lo menos otros agentes económicos adquieran por cualquier medio el control directo o indirecto de todo o de parte de más agentes económicos; $y$

c) Cualquier otro acuerdo o acto que transfiere en forma tácita o jurídica a un agente económico los activos de una empresa o le otorgue influencia determinante en la adopción de decisiones de administración ordinaria o extraordinaria de una empresa.

En este artículo se enumeran procedimientos que se pueden utilizar con el fin de concentrarse. Se hace referencia a la fusión y la adquisición de control, pero además se recurre a otras figuras: integración y consolidación.

El literal (a) expresa que la integración es una forma de concentrarse. Es necesario aclarar que la doctrina maneja el concepto de integración como sinónimo de concentración. Sin embargo, Julio Pascual y Vicente expone lo siguiente sobre el concepto de integración (Pascual y Vicente, 2002:242):

Se utiliza este término como sinónimo de concentración empresarial, aunque, a veces, se aplique en un sentido más restringido haciendo referencia únicamente a los procesos de fusión....

Orúe (2008:200), para establecer una diferencia entre los conceptos de fusión e integración, cita lo que la Ley General de Cooperativas (Nicaragua), en su artículo 94, expone sobre el proceso de integración:

Una o varias cooperativas podrán incorporarse a otra, conservando la incorporante su personalidad jurídica y extinguiéndose la de las incorporadas. El activo y el pasivo de éstas se transfiere a la incorporante.

Orúe (2008) afirma que este proceso es conocido como fusión por absorción.

De manera que, cuando el artículo cita la fusión y la integración como dos operaciones distintas, podría referirse a que la fusión se realizará por medio de la creación de una nueva persona jurídica y, en el caso de la integración, se sugiere el proceso de absorción.

Otro concepto que plantea cierta interrogante es la consolidación. Uno de los problemas que podría presentar un grupo de sociedades es la información financiera. El instrumento del que se dispone para tratar de solucionar este problema de información es la consolidación contable (Uría et al., 1999:1346). El objetivo que se busca mediante este tipo de consolidación es aclarar y corregir las distorsiones que genera la contabilidad separada de cada sociedad, ya que no es la forma idónea para mostrar la realidad económica del grupo. 
La lógica consiste en ofrecer la situación patrimonial y financiera del grupo como si fuera una única empresa (Uría et al., 1999:1346). Por ende la consolidación no es una figura que tenga por finalidad la concentración, su objetivo es mostrar los resultados financieros de un grupo de empresas que se encuentran concentradas.

Con respecto a la fusión, Julio Pascual y Vicente (2002:224) expone que es la transferencia del patrimonio de una o más sociedades a otra sociedad preexistente, $o$ bien a una sociedad de nueva creación que las absorbe. Es una operación que las empresas realizan para alcanzar mayor tamaño, desarrollando las actividades existentes, o bien, otras nuevas, con el fin de lograr mayor penetración en los mercados habituales o mercados nuevos. Un elemento importante a destacar en las operaciones de fusión es que entrañan una desaparición de personalidades jurídicas.

Por otro lado, en el caso de las adquisiciones de control, Julio Pascual y Vicente (2002) explica que es la compra total o parcial por una empresa de la propiedad y el control ${ }^{5}$ de otra. Las adquisiciones dejan intactas las personalidades jurídicas, sin embargo, el control de la adquirida cambia de manos. En los casos de adquisiciones es normal que las empresas sigan desarrollando por separado sus actividades respectivas. Es importante enfatizar que el control de una sociedad por otra se traduce en una maximización conjunta de beneficios.

Las concentraciones por adquisición de control implican que una o varias personas físicas, entidades privadas, solas o conjuntamente, adquieren la posibilidad de ejercer influencia sobre otra empresa por cualquiera de las siguientes maneras: compra de derechos de propiedad y relaciones comerciales tales como la situación de dependencia económica derivada de acuerdos de suministro.

En suma el artículo 24 menciona varias figuras, pero además se refiere a elementos importantes como pérdida de independencia económica y unidad de dirección, lo que conlleva a un cambio de estructura permanente en el funcionamiento de las empresas y ocasiona un cambio en la estructura del mercado relevante ${ }^{6}$ debido a que existe una reducción de oferentes.

La Ley 601 trata de conceptualizar lo que se entiende por concentración en su artículo 24, sin embargo deja claro que no son prohibidas, y que no todos los proyectos concentrativos generan la obligación de solicitar la autorización de su ejecución a PROCOMPETENCIA. Es el artículo 25 de la ley 601 el que establece aquellas concentraciones sujetas a notificación. El artículo expresa que aquellas operaciones que den como resultado que las empresas concentradas adquieran o incrementen una cuota igual o superior al 25\% del mercado relevante están sujetas a notificación previa ante PROCOMPETENCIA. Sigue exponiendo el mismo artículo que cuando agentes económicos que tengan ingresos brutos combinados superiores a un promedio de 642, 857 salarios mínimos, quieran fusionarse, también tendrán la obligación de solicitar la debida autorización a PROCOMPETENCIA. El problema de la Ley es que no hace referencia sobre qué índice de concentración ${ }^{7}$ se utilizará. 


\title{
2.2. La notificación
}

Se define en este artículo que en Nicaragua se emplea el sistema de notificación previa obligatoria. En Panamá, en lo referente al análisis de las concentraciones económicas, el artículo 23 de la Ley 45, "Ley que dicta normas sobre protección al consumidor y defensa de la competencia y otra disposición”, habla sobre la verificación previa, sin embargo no parece establecer un carácter obligatorio. El artículo dice lo siguiente: "Antes de surtir sus efectos, las concentraciones podrán ser notificadas y sometidas, por el agente económico interesado, a la verificación de la autoridad"(Gobierno de la República de Panamá, 31 de octubre de 2007).

El artículo utiliza el término podrán. No parece establecer la notificación con un carácter verdaderamente obligatorio, aunque el artículo 24 de la misma ley de Panamá expone sobre los efectos de la verificación y establece categóricamente el hecho de que aquellas operaciones aprobadas no pueden ser impugnadas. Por otro lado, aquellas concentraciones que no cuenten con la autorización de la autoridad competente corren el riesgo de ser desmanteladas.

Un elemento importante para destacar es el hecho que el artículo 25 de la Ley 601 aplica los criterios de obligatoriedad en la notificación para aquellos proyectos de concentración que se puedan realizar entre agentes económicos competidores, esto es, entre empresas que se encuentran en la misma fase del proceso productivo. Julio Pascual y Vicente ofrece la siguiente definición:

\begin{abstract}
Se dice que una integración es horizontal cuando la empresa que es resultado de aquélla cubre con mayor amplitud la misma fase del proceso productivo que antes cubrían las empresas que se han integrado. Por ejemplo, la integración de dos sociedades dedicadas ambas a la distribución de carburantes (Pascual y Vicente, 2002:242).
\end{abstract}

En Nicaragua se puede hablar del caso ESTESA, que fue absorbiendo a otras compañías que se dedicaban a brindar servicios de televisión por cable hasta alcanzar gran poder en el mercado. Se otorga prioridad a este tipo de concentraciones porque son las que pueden resultar más dañinas para la estructura del mercado. A partir de estas operaciones se pueden fijar posiciones de dominio ${ }^{8}$, monopolios ${ }^{9}$, monopsonios $^{10}$, duopolios ${ }^{11}$, oligopolios ${ }^{12}$, oligopsonios $^{13}$, o bien, monopolios conjuntos ${ }^{14}$.

La intención es evitar que en un mercado se produzca una estructura que dé como resultado la competencia imperfecta. El caso extremo de la competencia imperfecta es el monopolio. En la actualidad es raro que se encuentre un verdadero monopolio, se afirma que sólo existen cuando son protegidos de alguna manera por el Estado. Ejemplo: Una compañía farmacéutica que descubra un nuevo y maravilloso fármaco recibe una patente que le da el control monopolístico de ese medicamento durante unos años (Samuelson \& Nordhaus, 1999:161). Otro ejemplo es el de las empresas que se dedican a ofrecer algún servicio público y por ende necesitan una licencia para poderlo hacer. En Nicaragua el INE (Instituto Nacional de Energía) es el encargado de brindar los permisos en ese sector, tal es el caso de UNION FENOSA. 
Una de las causas de la competencia imperfecta, se debe a la situación en la que algunas empresas obtienen economías de escala, que significa el nivel óptimo de producción de una empresa y se da cuando ésta produce más a menor costo. Las pequeñas empresas no pueden hacerle frente a esta situación y sencillamente no pueden sobrevivir (Samuelson \& Nordhaus, 1999:163).

En muchos de los casos, cuando los proyectos de concentración económica se deben notificar, necesitan justificar por qué se quieren concentrar. Un efecto favorable es lograr eficiencia ${ }^{15}$ por medio del esfuerzo conjunto. Es decir, al concentrarse puede ser más factible obtener economías de escala, y esto se traduce a un mejor precio para los consumidores. Hay que destacar que lo anterior supone la satisfacción de los consumidores, que son eje fundamental en todo análisis del Derecho de competencia. Sin embargo, a mediano o largo plazo, es posible que esa economía de escala sea la causa de que otras empresas necesiten retirarse del mercado por el hecho de no poder competir contra ese ritmo de producción. Es por esta razón que los mercados pueden ir teniendo reducción de agentes oferentes y por ende los consumidores observan cómo sus posibilidades de elección son mínimas.

En este punto es preciso señalar que una empresa que se posiciona con poder en el mercado, no importando los medios, lógicamente puede disminuir su ritmo de producción por el hecho de no tener competencia y puede determinar las condiciones del mercado. Puede imponer precios o fijar precios de manera colusiva con otras empresas que también tienen una fuerte cuota de mercado. Además, pueden repartirse el mercado, limitar la producción y realizar un sinnúmero de acuerdos dañinos para los consumidores.

Es por esta razón que en el caso de las concentraciones se establece el sistema de notificación previa, para analizar y evitar cualquiera de las estructuras que resulten dañinas a la competencia efectiva.

En el artículo 26 de la Ley 601 ya se habla de prohibir las concentraciones, de manera que es muy claro que el legislador, para evaluar estas operaciones, utiliza la regla de la razón ${ }^{16}$. Algunas concentraciones se necesitan notificar y otras son prohibidas per se.

El artículo 26 expresa literalmente:

Quedan prohibidas las concentraciones de agentes económicos cuyo efecto sea o pueda ser disminuir, restringir, dañar o impedir la libre competencia económica respecto de bienes o servicios iguales, similares o sustancialmente relacionados. Se exceptúan de esta prohibición las concentraciones que recaigan sobre un agente económico que se encuentre en estado de insolvencia. Para los efectos de este capítulo, no se consideran como concentraciones, las asociaciones que se realicen por un tiempo definido para desarrollar un proyecto determinado.

En principio el artículo habla sobre los efectos de las concentraciones (regla de la razón), si éstos son disminuir, restringir, dañar o impedir la libre competencia, las concentraciones se prohíben. Cabe señalar que muchas concentraciones logran generar mayor competitividad en el mercado. Tal sería el caso de una industria compuesta por seis empresas, dos de las 
cuales tienen el 70\% como cuota de mercado y entre las otras cuatro se reparten el 30\% del mismo. Si las empresas que poseen el 70\% deciden actuar de manera colusiva podrían explotar su posición de dominio. Esta situación podría ser combatida si las otras empresas que representan el 30\% de la industria deciden actuar de manera conjunta para poder competir contra ese poder y además generar economías de escala y evitar ser eliminadas del mercado. Esto es una suposición porque bien podría generarse un monopolio conjunto (situación del mercado en la que un oligopolio actúa de manera colusiva para obtener beneficios monopólicos).

\subsection{Las concentraciones de tipo vertical}

Cuando el artículo 26 habla de bienes o servicios iguales, similares o sustancialmente relacionados, se refiere a concentraciones de tipo horizontal. Éstas ya se explicaron en párrafos anteriores de este artículo. A partir de esto es preciso apuntar que no se habla de las concentraciones de tipo vertical o de los conglomerados. No se definen lineamientos de análisis para este tipo de operaciones que también pueden generar problemas a la libre competencia.

Las concentraciones de tipo vertical ${ }^{17}$ son aquellas que se realizan entre empresas que se encuentran en diferentes escalones del proceso productivo y de distribución ${ }^{18}$. Expone Orúe (2008:213) que en vista de la adquisición de una empresa proveedora por una empresa cliente se puede limitar a los competidores la accesibilidad al mercado de los suministros. Se puede presentar esta situación en el sector de las farmacias. Si una farmacia se encuentra integrada verticalmente con un laboratorio, podría vender a muchos menores costos a los consumidores porque generan eficiencia transaccional ${ }^{19}$. Por otro lado, el contrato de suministro podría tener una cláusula en la que se prohíba que el laboratorio surta de productos a otras farmacias, o se establezca que les venda a un costo más alto, falseando así la libre competencia. En este punto, esta farmacia ofrece mejores precios a los consumidores por la antes descrito, sin embargo, a largo plazo puede ocasionar la quiebra de otras farmacias, y esto disminuye las opciones de los consumidores. A largo plazo puede generar que el número de oferentes se reduzca y dé como resultado posiciones de dominio que afecten el bienestar del consumidor.

\subsection{El conglomerado}

Otro tipo concentración que no es abordado en el artículo 26 de la Ley 601 es el conglomerado, aunque en el artículo 24 del mismo cuerpo jurídico, cuando se habla de consolidación, se refiere a la unificación de estados financieros de un grupo empresarial.

El conglomerado es un grupo de empresas que se encuentran concentradas y cada una de ellas ejerce su actividad en sectores distintos de las demás. Este tipo de concentraciones ofrece ventajas tales como: reducir el riesgo general, facilitar la movilización de capitales y de recursos humanos, y obtener una mejor asignación de los medios de producción (Pascual y Vicente, 2002:165). Por otro lado, los conglomerados constituyen un buen panorama para realizar prácticas anticompetitivas. Se pueden otorgar subvenciones cruzadas con el único objetivo de eliminar la competencia en algunos sectores. 
Pensemos en un banco como empresa matriz del grupo. El grupo está conformado por empresas de distintos sectores pero una de ellas se dedica al sector construcción. Si el banco adopta la posición de subvencionar la actividad de ésta, podría dar como resultado que la empresa constructora tenga una gran ventaja sobre sus competidores directos debido al poder financiero que la respalda y por ende puede eliminar en gran medida la competencia en el sector construcción.

El legislador debió hacer alguna referencia directa sobre este tipo de concentraciones y no abordarlas como si sólo se trataran de operaciones de tipo horizontal, es decir, entre agentes económicos competidores.

\subsection{Análisis y prohibición de las concentraciones}

El artículo 28 del Reglamento a la Ley 601 establece los criterios para prohibir las concentraciones; enumera los siguientes:

1. El ámbito del mercado relevante donde actualmente produce efectos.

2. Elámbito del mercado relevante donde eventualmente producirá efectos la concentración con respecto a competidores y demandantes del bien o servicio, como en otros mercados y agentes económicos relacionados.

3. El control de los agentes económicos involucrados.

4. La posición de dominio que habría de resultar de producirse la concentración.

5. La valoración en eficiencia económica que pueda resultar de la concentración.

Se establece como punto de partida para el análisis de la concentración el estudio de la estructura del mercado relevante. Es preciso definir el o los mercados que se verán afectados por la concentración con la finalidad de determinar si dicha operación limita o no la competencia. La definición de mercado relevante se refiere a dos dimensiones, el mercado relevante del producto y el mercado relevante geográfico.

Este análisis debe hacerse desde dos puntos fundamentales, demanda y oferta. El análisis de la demanda debe tener en cuenta que los productos objeto del análisis deben ser sustituibles desde la perspectiva de los consumidores. Por otro lado, el análisis también debe tomar en cuenta a los actuales oferentes del bien o servicio y aquellos agentes económicos que con facilidad pueden producir el bien servicio (Pascual y Vicente, 2002:270).

Pascual y Vicente (2002:270) expone lo siguiente:

En el mercado relevante se consideran habitualmente comprendidas a las empresas que efectivamente produzcan los bienes objeto de atención, que son las vendedoras efectivas; y también a las vendedoras potenciales, es decir, a las empresas que pueden rápidamente modificar sus líneas de producción para proveer los bienes de referencia o sus sustitutos si el precio es suficientemente atractivo.

La afirmación anterior es comprendida por el numeral 2 del artículo 25 del Reglamento a la Ley 601, que expone que el análisis del mercado relevante comprende incluso aquellas empresas que pueden llegar a producir el bien en cuestión en un corto tiempo. 
Si el bien producido por las empresas que se concentran tiene sustituto, el poder de mercado de ésta se ve reducido, de manera que la conducta de los consumidores es fundamental pues son éstos los que determinan qué bienes consideran sustitutos.

Por otro lado, con respecto al estudio del mercado relevante geográfico, se debe tomar en cuenta qué empresas son las que ofrecen el bien o servicio en esa zona; desde el punto de vista de la demanda (usuarios, consumidores), si ésta puede adquirir ese bien o servicio en una zona geográfica cercana pero distinta a la zona geográfica donde eventualmente producirá efectos la fusión. Se toman en cuenta las dos zonas geográficas con el único fin de poder determinar el grado de sustituibilidad que tiene el bien o servicio objeto de la concentración económica ${ }^{20}$.

Siguiendo con el análisis de los criterios que ofrece el Reglamento a la Ley 601 en referencia a la regulación de las concentraciones, se debe hacer un estudio que defina y determine el nivel de control que tienen las empresas próximas a concentrase dentro del mercado relevante. En este sentido es necesario observar paralelamente el artículo 27 de la Ley 601 que dice literalmente:

En la investigación de concentraciones se deberá determinar entre otros criterios que el acto o la tentativa: a) Confiera o pueda conferir al agente económico resultante de la concentración, el poder de fijar precios unilateralmente o restringir sustancialmente el abasto o suministro en el mercado relevante, sin que los agentes competidores puedan, actual o potencialmente, contrarrestar dicho poder.

A partir de los criterios que ofrecen la Ley y el Reglamento se puede afirmar que es necesario determinar qué poder tendrán las empresas en el momento que se concentren; es decir, sin son capaces de imponer condiciones de manera unilateral o conjunta, esto es en dependencia de la estructura del mercado. Puede ser que se trate de un oligopolio o un monopolio, además bien puede surgir una posición dominante. Para este estudio es necesario identificar a las empresas que operan en el mercado y calcular sus participaciones, sus cuotas de mercado, que como ya se expuso, esto se hace posible mediante índices de concentración que debieron definirse en la Ley o el Reglamento ${ }^{21}$.

\subsubsection{Las barreras}

En ese mismo estudio de mercado es fundamental visualizar las barreras de entrada. Así lo establece el artículo 25 del Reglamento. Esto se debe a que dichas barreras de entrada pueden aumentar la concentración en un mercado. Una barrera de entrada es un factor que dificulta el ingreso de nuevas empresas a determinado mercado, las economías de escala son un tipo habitual de barrera, pero además pueden existir restricciones legales y elevados costos de entrada. En seguida se explican algunas barreras (Samuelson \& Nordhaus, 1999:165-166):

Restricciones legales: En muchos casos los poderes públicos pueden limitar la competencia en determinadas industrias. Ejemplos de esta situación son las patentes y los aranceles sobre el comercio exterior. El Estado, con el ánimo de fomentar la invención, concede monopolios 
basados en patentes. También es necesario mencionar que el Estado en ocasiones concede monopolios por licencia a empresas que se dedican a proporcionar servicios públicos.

Elevados costes de entrada: Además de las barreras impuestas por la ley, se encuentran aquellas barreras económicas. Esto se debe a que en algunas industrias se requiere realizar una inversión muy alta para poder ingresar a ese mercado y constituirse en un agente económico. Las economías de escala desarrolladas por empresas poderosas imponen condiciones básicas en esas industrias para que otras empresas puedan competir.

En conclusión, los monopolios naturales ${ }^{22}$ y legales ${ }^{23}$ constituyen barreras de entrada. Por otro lado, si una empresa ha alcanzado un nivel óptimo de producción, en el que se produce en gran cantidad y calidad a bajos costos, también se convierte en una fuerte barrera de entrada.

En suma, estudiar las barreras de entrada resulta fundamental en el análisis del mercado relevante previo a la autorización de una concentración. Esto es con el objetivo de observar con qué dificultad o facilidad podrían otras empresas entrar en esa competencia y por ende desconcentrar ese mercado.

\subsubsection{La eficiencia}

Otro elemento que requiere especial observación es la eficiencia. Si las empresas que proponen concentrarse demuestran que su principal objetivo es alcanzar niveles de eficiencia que beneficiarán a los consumidores es probable que la fusión o adquisición de control sea permitida.

El artículo 23 del reglamento a Ley 601 se refiere a la eficiencia. Además, el literal b) del artículo 4 de la Ley establece que las actividades entre agentes económicos que tengan por objeto lograr mayor eficiencia en la actividad productiva se consideran como excepciones para la aplicación de las disposiciones legales siempre que no configuren ninguna conducta prohibida.

En seguida se ofrecen algunas consideraciones importantes sobre la eficiencia. Para la consideración de las eficiencias dentro del marco jurídico de la competencia, algunos juristas se inclinan por definir competencia como una situación que debería tener el objetivo de lograr bienestar social. En general, se puede decir que bienestar social es la satisfacción que obtienen productores y consumidores. El bienestar del productor se mide por su excedente, es producir algo a un costo y venderlo más caro, y por otro lado, si los consumidores consiguen los bienes que necesitan más baratos de lo que en última instancia estarían dispuestos a pagar, es bienestar del consumidor o usuario (Comisión Federal de Competencia, 2004:46-54).

Se considera que una empresa será técnicamente más eficiente que otra, si fabrica una misma cantidad de productos utilizando menos cantidad de factores de producción. Por otro lado, una empresa será más eficiente que otra, si utilizando los mismos procesos productivos, una de ellas alcanza un nivel de producción que le permite desarrollar economías de escala (Pascual y Vicente, 2002:204). 
Es preciso mencionar que la doctrina reconoce que existen eficiencias estáticas (es el costo más bajo posible en el proceso de producción) y eficiencias dinámicas, que se refieren al proceso mediante el cual las empresas, en su afán de superar a sus rivales, desarrollan novedosos procesos productivos, es decir, que emprenden actividades de investigación y desarrollo con el objetivo de obtener mayores beneficios (diferencia entre los costos y los ingresos).

Por ende, que las empresas demuestren las eficiencias que se lograrán a partir de la concentración es un punto importante para que PROCOMPETENCLA autorice el proyecto.

\section{Conclusiones}

El tema de las concentraciones de empresas requiere de un complejo proceso de análisis. No se puede describir un panorama totalmente negativo en cuanto a los posibles efectos de las concentraciones en el mercado, como tampoco podemos referirnos al tema únicamente en relación con sus beneficios.

El objetivo fundamental de las normas de control de las concentraciones de empresas es subordinar la ejecución de las operaciones de concentración a una autorización administrativa que funcione a partir de criterios objetivos establecidos por la ley. En Nicaragua se implementa un sistema de notificación y solicitud de autorización previa, pero sólo cuando se igualen o superen los umbrales a los que se refiere el artículo 25 de la Ley 601. Esto quiere decir que en principio existe libertad para concentrarse.

El sistema de notificación previa establecido en la Ley 601 y su Reglamento tiene la finalidad de realizar un balance entre los posibles beneficios que se generen a partir de la concentración y los efectos negativos.

Se toma en consideración si como resultado de la operación se logra que las empresas produzcan al menor costo posible, si se generan incentivos en las empresas para emprender más actividades de investigación y desarrollo. Es conveniente apuntar que el bienestar de los consumidores es un objetivo central de la política de competencia y muy a menudo se utiliza como una guía para la aplicación de las normas que regulan el comportamiento de las empresas en el mercado.

Por otro lado, se analizan los efectos negativos que pueda tener la concentración en la competitividad del mercado. Se trata de evitar que las empresas alcancen o refuercen una posición de dominio en el mercado que les permita determinar el funcionamiento de éste, imponiendo alzas en los precios y condiciones comerciales no equitativas. Cabe destacar que la Ley 601 faculta a PROCOMPETENCIA para autorizar la solicitud de concentración, para no autorizarla y para autorizarla de manera parcial o condicionada. Es decir, que en algunos casos, cuando la operación de concentración proporcione a las empresas cierta condición que les permita realizar conductas que afecten el mercado, se les establece una obligación de llevar a cabo determinada conducta o de abstenerse.

Finalmente, en cuanto al ordenamiento que la Ley 601 establece, se pone de manifiesto la función preventiva y ordenadora de esta regulación que no tiene como propósito fundamental 
prohibir las operaciones de concentración, sino que trata de impedir que a partir de la concentración se produzcan efectos lesivos para la competencia y el buen funcionamiento de determinado mercado.

\section{Recomendaciones}

En la Ley 601, con respecto a su objeto, mismo que es determinado en el artículo 1, es importante destacar que sólo se hace mención de la prevención, prohibición y sanción de prácticas anticompetitivas, por lo que se sugiere recoger en su fundamento la regulación de las concentraciones de empresas pues éstas no suponen una práctica anticompetitiva y en este caso se trata de un cambio en la estructura de un mercado.

Es necesario que la Ley 601 trate de definir con más precisión los conceptos a los que se refiere el artículo 24 de la misma en cuanto a lo que se considera concentración empresarial. Se enumeran varias operaciones como fusión, adquisición, consolidación; la doctrina explica que el objetivo de recurrir a los criterios de enumerar las operaciones que se utilizan para concentrarse es crear cierta certeza jurídica para poder determinar el ámbito de aplicación de la norma, situación que no se logra cuando la Ley no deja claro los conceptos.

En lo referente al artículo 25 de la Ley, cuando especifica los umbrales, establece que la concentración quedará sujeta a la obligación de notificar cuando como consecuencia de la operación se adquiera o se incremente una cuota igual o superior al 25\% del mercado relevante. En este aspecto sería útil señalar cómo será el procedimiento para determinar el grado de concentración que se obtendrá a partir de la operación, se debería sugerir la utilización de algún índice de concentración.

Finalmente, cuando se habla de regular las concentraciones de empresas, y los criterios que se utilizarán para su evaluación, se observa que la Ley y el Reglamento, con respecto al tema que nos ocupa, no gozan de amplitud y precisión. Por lo tanto, con el objetivo de crear claridad en los criterios de valoración, se debería implementar en un futuro una guía de concentraciones en la que se especifiquen los índices de concentraciones que podrán aplicarse.

\section{Notas}

1 Actualmente en los países occidentales la mayoría de las decisiones se toman en el mercado, pero el Estado juega un papel importante en la supervisión de su funcionamiento, aprueba leyes y regula la vida económica, produce servicios educativos y policiales y controla la contaminación. Actualmente, la mayoría de las sociedades poseen una economía mixta (Samuelson \& Nordhaus, 1999:8).

2 El bienestar social está compuesto por el bienestar del consumidor y el del empresario oferente.

3 Genéricamente se aplica este término a un gran número de prácticas comerciales que tienen por objeto o efecto restringir la competencia entre las empresas. En España, la Ley de Defensa de la Competencia distingue tres categorías de prácticas anticompetitivas constitutivas de conductas prohibidas: Las colusorias, las abusivas y los actos desleales contrarios a la libre competencia. (Pascual y Vicente, 2002 2 :154). 
4 El control de las concentraciones es un mecanismo para prevenir los efectos negativos que pueden ocasionar a la competencia efectiva, por supuesto distinto al que se utiliza para analizar carteles o prácticas abusivas de aquellos que tienen poder de mercado. En estos casos el Estado actúa de forma represiva y posterior a la práctica por medio de la potestad de sancionar. En el caso del control de las concentraciones generalmente se actúa de manera preventiva (Instituto Nacional de Defensa de la Competencia y de la Protección de la Propiedad Intelectual (2005:162).

5 Se considera que hay control de una sociedad cuando una persona o un grupo de inversores detentan más del 50 por 100 de las acciones ordinarias con derecho de voto de dicha sociedad. Puede haber control cuando los inversores detentan un paquete de acciones inferior al 50 por 100, sin embargo, en este caso el resto del capital tiene que estar repartido en un gran número de pequeños accionistas. (Pascual y Vicente, 2002:176). Como regla general, se entiende que una sociedad controla a otra cuando, siendo socio de la misma, posea la mayoría de los derechos de voto o tenga la facultad de nombrar o destituir a la mayoría de los miembros del órgano de administración de aquella. (Uría et al., 1999: 312).

6 También es llamado mercado de referencia y mercado pertinente. El punto de partida para todo análisis de la competencia es la definición del mercado relevante, cuyos dos elementos son el mercado de productos que deben ser considerados como integrados en él y el mercado geográfico o zonas que deben ser consideradas partes del mismo. La definición del mercado relevante debe hacerse tanto desde el punto de vista de la demanda como desde la perspectiva de la oferta. En lo que concierne a la demanda, los productos integrantes en el mismo deben ser sustituibles desde la perspectiva del consumidor. De lado de la oferta se tendrán que considerar las empresas que produzcan o puedan fácilmente producir el producto considerado o sus sustitutos (Pascual y Vicente, 2002:270).

7 Son instrumentos creados por los economistas para intentar describir la estructura del mercado y dar una idea del poder de las empresas en el mismo. Los índices de concentración esencialmente miden el número y la distribución estadística de los tamaños de las empresas. Los índices más frecuentes son los siguientes: índice Herfindahl - Hirschman, curva Lorenz, coeficiente de Gini, índice inverso y coeficiente de entropía. (Pascual y Vicente, 2002:235)

8 La empresa que dispone de tal posición puede actuar sin necesidad de tener en cuenta las reacciones que su comportamiento suscite en el mercado. La posición de dominio es, en primer lugar, un poder económico, es decir, la facultad que tiene cada empresa dominante de ejercer sobre el funcionamiento del mercado una influencia notable y en principio previsible (Pascual y Vicente, 2002:304).

9 Situación de un mercado en la que hay un solo vendedor, el concepto de monopolio se opone al de competencia perfecta (Pascual y Vicente, 2002:271).

10 Situación en el mercado en la que existe un solo comprador (monopolio de demanda) (Pascual y Vicente, 2002:275).

11 Situación del mercado en la que un sector de actividad únicamente comporta la existencia de dos vendedores, se trata de un caso particular de oligopolio (Pascual y Vicente, 2002:200).

12 Situación del mercado que se caracteriza por la existencia de un número muy limitado de vendedores que tienen conciencia de ser interdependientes en sus decisiones de precios y de producción (Pascual y Vicente, 2002:284).

13 Se trata de una situación en el mercado en la que hay un número muy limitado de compradores (Pascual y Vicente, 2002:285).

14 Se aplica este término para denominar el comportamiento anticompetitivo que pueden adoptar las empresas participantes de un oligopolio con el fin de obtener rentas de monopolio (Pascual y Vicente, 2002:272).

15 Es la utilización óptima de los recursos existentes en una sociedad para satisfacer las demandas de los consumidores al costo más bajo posible (Schatan \& Ávalos, 2006:78).

16 Se utiliza con el fin de no prohibir los meros actos, lo que se trata de evitar son las consecuencias negativas de éstos, y para eso se necesita realizar una evaluación de la eficiencia que se puede producir a partir de ciertas conductas, así como sus efectos negativos. 
17 Una cervecería puede tener sus propias plantas de producción de botellas de vidrio y de todos los insumos que necesita para la cerveza (Instituto Nacional de Defensa de la Competencia y de la Protección de la Propiedad Intelectual, 2005:85).

18 En la ley 182, Ley de Defensa de los Consumidores, en su artículo 4, literal b), se enumeran los distintos escalones del proceso productivo: “...producción, fabricación, importación, distribución o comercialización...”.

19 Reducir costos de transacción con sus proveedores. (Instituto Nacional de Defensa de la Competencia y de la Protección de la Propiedad Intelectual, 2005:85).

20 Artículo 24, numeral 4, Reglamento a la Ley 601.

21 No todos los índices dan el mismo y exacto resultado, tienen pequeñas variaciones debido a que algunos están diseñados para calcular el panorama global de una industria y otros para identificar a las empresas más poderosas del mercado.

22 Hay un monopolio natural en un mercado cuando las condiciones existentes en el mismo son tales que una sola empresa produce a más bajos costos que si hubiera una pluralidad de ellas (Pascual y Vicente, 2002:274).

23 Es el monopolio resultante de un privilegio concedido por el Estado mediante la Ley (Pascual y Vicente, 2002:273).

\section{Referencias bibliográficas}

COMISIÓN FEDERAL DE COMPETENCIA (2004). Competencia económica en México. México: Porrúa, S.A., $1^{\mathrm{a}}$ ed.

GOBIERNO DE LA REPÚBLICA DE NICARAGUA (24 de octubre de 2006) Ley No. 601: De promoción de la competencia, aprobada el 28 de septiembre de 2006. Managua: La Gaceta Diario Oficial No. 206.

GOBIERNO DE LA REPÚBLICA DE NICARAGUA. (2006) Reglamento a la Ley No. 601, Decreto No.79-2006 del 15 de enero de 2007, Managua: La Gaceta Diario Oficial No.10.

GOBIERNO DE LA REPÚBLICA DE PANAMÁ (7 noviembre de 2007) Ley No. 45: Normas sobre la protección al consumidor y defensa de la competencia y otra disposición, aprobada el 31 de octubre de 2007. La Gaceta No. 25914: Ciudad de Panamá.

INSTITUTO NACIONAL DE DEFENSA DE LA COMPETENCIA Y DE LA PROTECCIÓN DE LA PROPIEDAD INTELECTUAL (2005) Legislación y Políticas de Competencia en la Comunidad Andina. Lima: Indecopi, $1^{a}$ ed.

MÉNDEZ MORALES, J. (1996). Fundamentos de Economía, México: McGraw-Hill, $16^{\mathrm{a}}$ ed.

ORÚE CRUZ, J. R. (2008). Derecho de competencia: Una introducción, Managua: Lea Grupo Editorial, $1^{\mathrm{a}}$ ed.

PASCUAL Y VICENTE, J. (2002). Diccionario de Derecho y Economía de la Competencia en España y Europa, Madrid: Civitas.

SAMUELSON, P. \& NORDHAUS, W. (1999). Economía, Madrid: McGraw-Hill, $16^{\text {a }}$ ed.

SCHATAN, C. \& ÁVALOS, M. (2006). Condiciones y Políticas de Competencia. Economías Pequeñas de Centroamérica y El Caribe, México: CEPAL, $1^{\text {a }}$ Ed.

URÍA, R. ET AL. (1999). Curso de Derecho Mercantil, t.1, Madrid: Civitas, $1^{\mathrm{a}}$ ed. 